\title{
Economic behavior and behavioral economics at times of COVID-19 pandemic
}

\section{Doron Kliger ${ }^{1}$}

Received: 28 November 2020 / Accepted: 4 December 2020 / Published online: 2 September 2021

(c) The Author(s), under exclusive licence to Springer-Verlag GmbH Germany, part of Springer Nature 2021

\begin{abstract}
I am a behavioral economist, who is interested in both behavioral sciences and economic behavior. By the term "economic behavior" I refer to the calculative reasoned domain of economic analysis, whereas by "behavioral economics" I address aspects of human feelings, emotions and everything that is not captured by the "rational" paradigm. Evidently, erroneous calculations, as well as unhinged sentiments lead to economic losses, and every change in the economics of the world has both calculative and behavioral sides to it. In what follows, we examine these two sides of behavior in relation to the COVID-19 pandemic by drawing on contemporaneous data, forecasts, and images. Each side of behavior reveals distinctive insights, and intriguingly, not all outcomes count as loss. As we face this crisis, there is a clear environmental gain that we would be smart to preserve post pandemic.
\end{abstract}

\section{Economic behavior: forecasts and immediate reactions}

FORECASTS from recent Oxford Economics reports depict three scenarios ${ }^{1}$ for the world GDP (Oxford Economics2020 ). ${ }^{2}$ The red column in Fig. 1 on the first page of the Oxford Economics report shows the baseline, pre-coronavirus, scenario of projected real GDP growth. The blue column there is the updated baseline, i.e., taking into account COVID-19, indicating about 2.5\% decline in real GDP growth, and the yellow column presents the "downside" or "worst-case" scenario of about $4 \%$ decline, relative to the pre-coronavirus scenario.

\footnotetext{
1 This address has been written at the time when COVID-19 has just become a pandemic, i.e., a worldembracing epidemic. The information provided by the various data sources referred to herein have therefore to be interpreted accordingly.

${ }^{2}$ Research Briefing | Global, The global economy enters a short, sharp, recession. Available at: https:// www.oxfordeconomics.com/; report may be downloaded after subscription.
}

\section{Doron Kliger}

kliger@econ.haifa.ac.il

http://kliger.haifa.ac.il

1 Department of Economics, University of Haifa, Haifa, Israel 

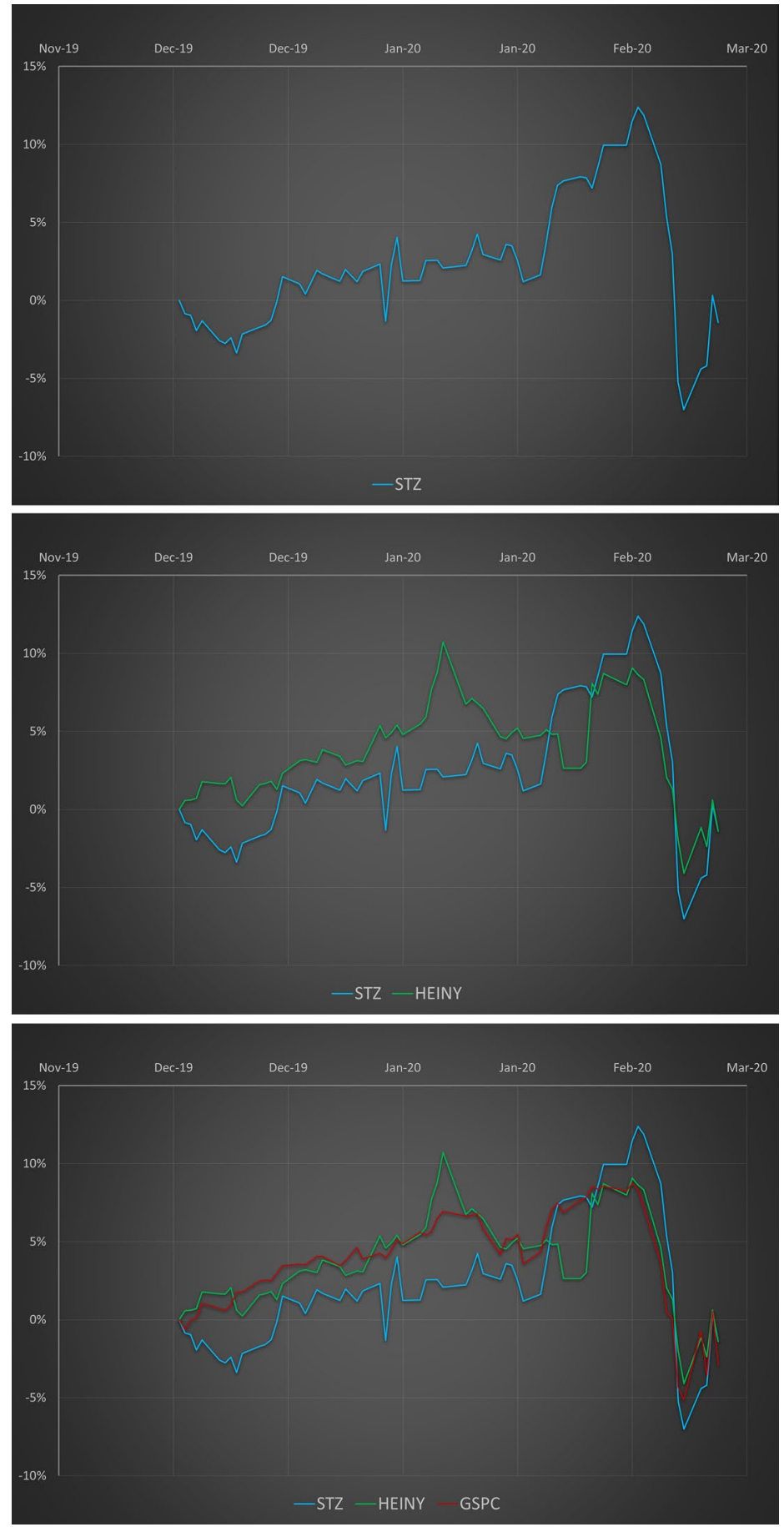

Fig. 1 Did Coronavirus affect Corona beer? 
Figure 1 on page 3 of the report presents a longer look into the future. It reveals a bright side to this grim projection, as it implies that the main damage is only temporary. This is reflected in a $0.2 \%$ projected permanent damage to the baseline, which can expand in the worst-case scenario to a roughly $1 \%$ decline in real GDP.

Other projections were developed by the OECD (OECD 2020). ${ }^{3}$ Their "contained" scenario, by now obsolete, was portrayed under the hope that the epidemic would be restricted more or less to the Far East, in which case the prediction was a - $0.5 \%$ full-year impact on 2020 world GDP; and their "downside" scenario, which is unfortunately coming true, predicts a corresponding impact of $-1.5 \%$.

Moving along the worst-case scenario is the bad news. The good news, as the projections claim, is that the economy is expected to recover from the crisis as soon as toward the end of the current year 2020.

IMMEDIATE REACTIONS to COVID-19 disrupted the "normal" flow of events around the world. Inspecting the website of Flight Radar 24 showed a sharp drop in air-flight departures from mainland China's busiest airports by mid February, 2020. Clearer skies have two major and opposing consequences: direct damage to the economy from the lost revenue in the airline industry and related economic activity, versus significantly cleaner air, reflected in the lower concentration of nitrogen dioxide in the air (among other pollutants). This is clearly (pun intended) seen in the map of mainland China just before the major air-traffic pandemic-related reduction, as opposed to during the pandemic, at the nitrogen dioxide emissions heatmaps provided by the NASA Earth Observatory. ${ }^{5}$ Worth viewing are photos of New Delhi that were taken from the same vantage points "then and now", showing the dramatic reduction in water and air pollution - the kind of changes resulting from the pandemic which we would want to preserve for the future to come (The Guardian 2020). ${ }^{6}$

\section{Behavioral economics: moods, emotions, and financial market activity}

AMERICAN AND EUROPEAN STOCK MARKETS reacted to COVID-19, from the beginning of the year till March, 23 (2020) in a plunge in the order of 30\% (S\&P 500 and FTSE, for instance, dropped $31 \%$ and $34 \%$, respectively). Interestingly, in the Far East, a plunge in prices was also observed, but the picture was much milder; the SSE 50 index, for example, went down "only" by $17 \%$ over the same period. Since then, markets have begun a slow return toward pre-plunge levels, such that the total damage by May 10, 2020, is about 10\%, 22\% and 7\%, for S\&P 500, FTSE, and SSE 50, respectively.

\footnotetext{
3 https://www.oecd.org/about/; report may be downloaded after subscription.

4 Source: Flightradar24.com, https://bit.ly/35Lwo0V.

5 See NASA Earth Observatory by Joshua Stevens, as appeared on euronews, https://bit.ly/3fAe13w.

6 The Guardian, April 11, 2020: https://bit.ly/2LfTgMz.
} 
THE INITIAL STOCK MARKET DECLINE was prominently larger than the forecasted plunge in future GDP. This is true also at the partial recovery by May 10, reported above. A behavioral perspective can help us better understand that gap. First, there may be some issues related to the underlying assumptions of the economic predictions. Indeed, earlier relatively mild predictions were followed later on by grimmer ones. Another reason for this discrepancy is that stock market participants may have panicked, which would have accounted for the sharp decline, followed by some recovery, as is evident, once the panic subsided. A third explanation that I would like to offer is of an inflated market that was actually "waiting" for some kind of a trigger in order to blow up. Indeed, equity markets had skyrocketed over the last few years, hence the suggestion here is that this "balloon" may have been waiting for a "pin" to burst it, and so the entire market coordinated around COVID-19 and "decided" jointly that it was time for prices to deflate down to more realistic values.

DID CORONAVIRUS AFFECT CORONA BEER? Have you heard stories that talk about the link between Corona beer and coronavirus, and describing the plunge in Corona beer prices as being due to the similarity in name? While looking at Fig. 1a, these stories may seem to be evidence-based, they are nothing more than fake news. Inspecting the stock prices of another very large beer manufacturer, Heineken (Fig. 1b), reveals the same trend. Indeed, it would be virtually impossible to differentiate between the graphs of the two stocks, were it not for the graph titles. Furthermore, comparing the beer company graphs to the S\&P 500 graph (Fig. 1c), we see that there is nothing special about the stock prices of Corona beer compared with the rest of the market.

HOW IS ZOOM FAIRING? We are all familiar with Zoom, which has become a household name in recent weeks. Take a look at, ZOOM (Fig. 2a), that skyrocketed in mid-April to more than $800 \%$ of its beginning-of-February value and, later on, declined sharply. The question is: what happened here, and what is ZOOM's real economic value? In fact, this graph describes the stock behavior of the wrong Zoom company. This company is a small technology company, not the video conferencing Zoom! Investors seeking opportunities rushed out to buy stock of what they thought to be the Zoom company and even after this mistake was publicized in the financial press, the company was still traded way above its price at the beginning of February, for quite a while.

Now let us look at the stock activity of the "correct" videoconferencing company, Zoom, whose ticker is simply ZM (Fig. 2b). As we can see, it went up, as well,... but "only" by $100 \%$ (there's a lot ongoing with ZM, you will probably learn more about it by the time this article is published).

HOW WOULD PEOPLE'S REACTION TO COVID-19 CHANGE OVER TIME? As elaborated by Daniel Kahneman and the Amos Tversky, when people are given a description of a rare event, they tend to overreact. At the beginning of the coronavirus pandemic, the world was given a description of what was going on in Hubei district in China, and shortly after that in Italy, including many vivid anecdotes. Correspondingly, people initially over-reacted. After a while, however, people might start getting used to the situation, and since many do not confront the virus directly, they might become indifferent. Nassim Taleb and Ido Erev, who studied 

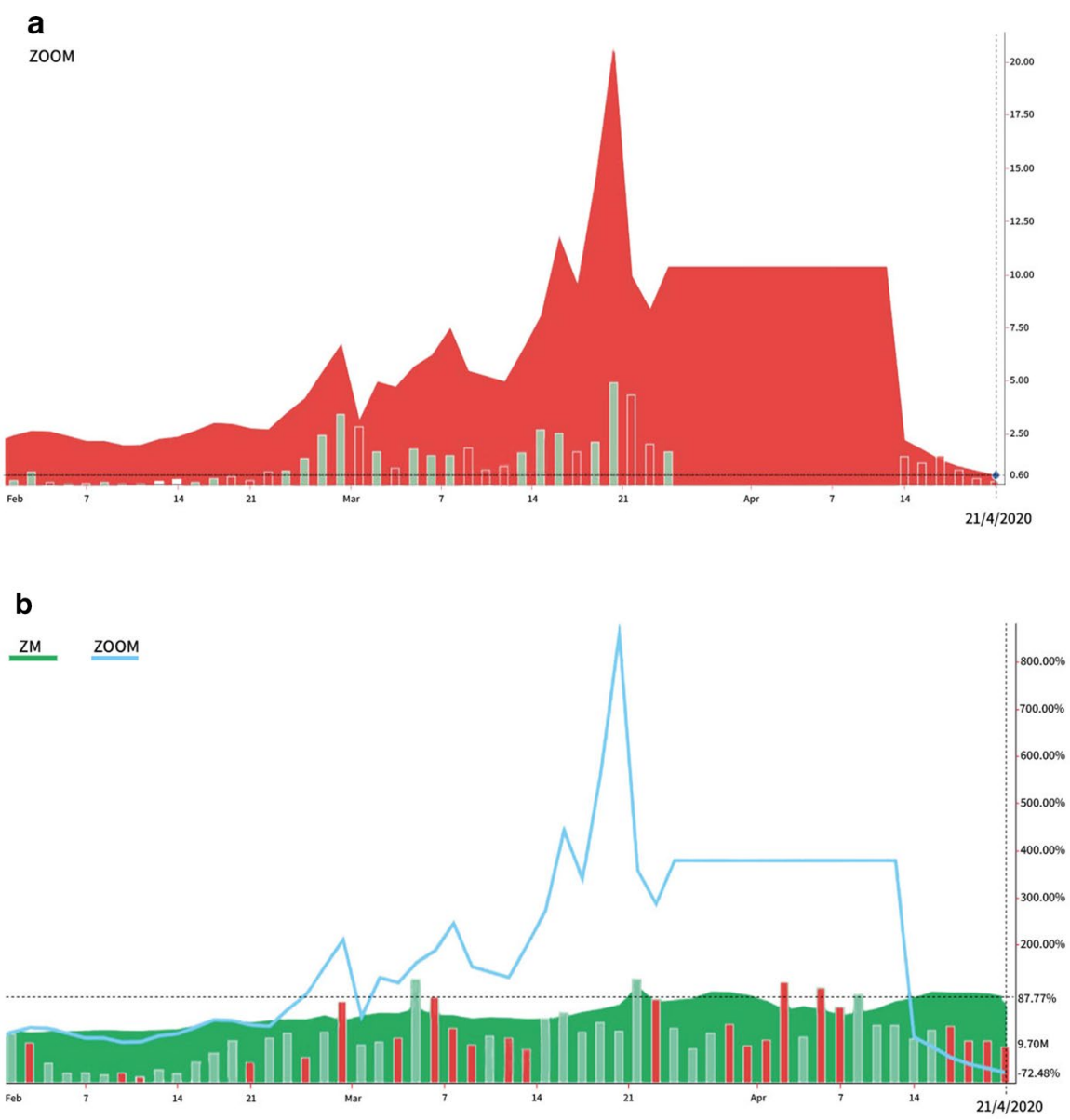

Fig. 2 How is Zoom fairing?

this issue, said that when people experience the rare events, they tend to underreact. For instance, in many industries, it is quite common to see experienced employees fail to use precautionary equipment. Why is that so? After several years of work most of them acknowledge that nothing happened to them so far, thus may ask themselves: so why should I continue wearing my helmet? They let the silent danger of indifference crawl in.

Nassim Taleb wrote a lot about "black swans", unanticipated events for which people do not prepare, and are then surprised when they occur. Noteworthy, COVID19 is NOT a black swan. Professionals knew that such a pandemic was due to happen, they just did not know when. Nevertheless, people reacted to COVID-19 as if it was totally unpredicted.

WHAT CAN WE DO? In situations of anxiety, we tend to have tunnel vision. At present, the world indeed is in a tunnel-vision situation: we see the pandemic, 
we think about the pandemic, we hear about the pandemic in the news, we talk to each other about the pandemic (if you read this article while the pandemic is still in the front pages, try this exercise: talk to a friend and try not to say the word "coronavirus" for as long as you can...). What we should do in such situations, is to remind ourselves that there is more happening in the world, many important things, in addition to or alongside the coronavirus situation. Some of these other things are positive, or changes for the better, which we want to stay for good. Many claim this duality is well expressed in the Chinese word for "crisis" being composed of two characters, one that signifies "danger", of which we are well aware, and the second that signifies "opportunity". ${ }^{7}$ With the COVID-19 crisis, we have the opportunity to change our behavior, to depart from routine, and to think outside the box. Maybe we should try to take some of these good things and think how we can preserve them for good, for the long run.

\section{Looking ahead: How to Preserve the "Good" Changes?}

Unfortunately, collective memory of historical crises is short. After returning to routines, people tend forget about positive changes and revert to the nitty-gritty of daily life. Can we avoid the tendency this time around? Can we capture the good changes, and keep them for the long run?

I end this article with sharing two projects that provide a platform for noticing, aiming for, and making changes. Several years ago, I collaborated on a project with colleagues at the University of Haifa, Shira Zelber-Sagi and Mor Peleg. We obtained permission from the then-new President of our university, Prof. Ron Robin, to employ the university's Eshkol Tower, that is easily seen from dozens of kilometers around Haifa, for a couple of weeks, in order to convey a message (See Fig. 3). The project was called "Fresh Start" and the idea was to have a prominent event that would cause people to permanently change some of their behaviors and habits. For the first couple of nights, all lights in the tower were off except for the numeral 5, we have lighted by leaving the lights of several offices on. Some people noticed it, many did not. A few days later, we lit an additional numeral, 2, igniting the curiosity of university employees and people at large, who began asking questions about the lights. Subsequently, we disseminated a reply in the media that a dedicated website http://orot.haifa.ac.il/, was established for this secret project, in which people could post their guesses about the reason of turning the lights on. We promised symbolic prizes for correct participation, causing a noticeable buzz in the area, with numerous replies. After some more days, the lights of numeral 1 were appended and, finally, the entire riddle was played out on the tower by adding the numeral zero, such that 5 210 was presented on the building. What is 5210 ? People started to send in their answers, which included: The number of students at the University of Haifa (No!, it's more than 3 times larger); The birth date of Levi Eshkol, after whom the tower

\footnotetext{
7 While this alleged word-structure is a widespread public misperception (cf. http://www.pinyin.info/ chinese/crisis.html), it serves a well-deserved purpose.
} 


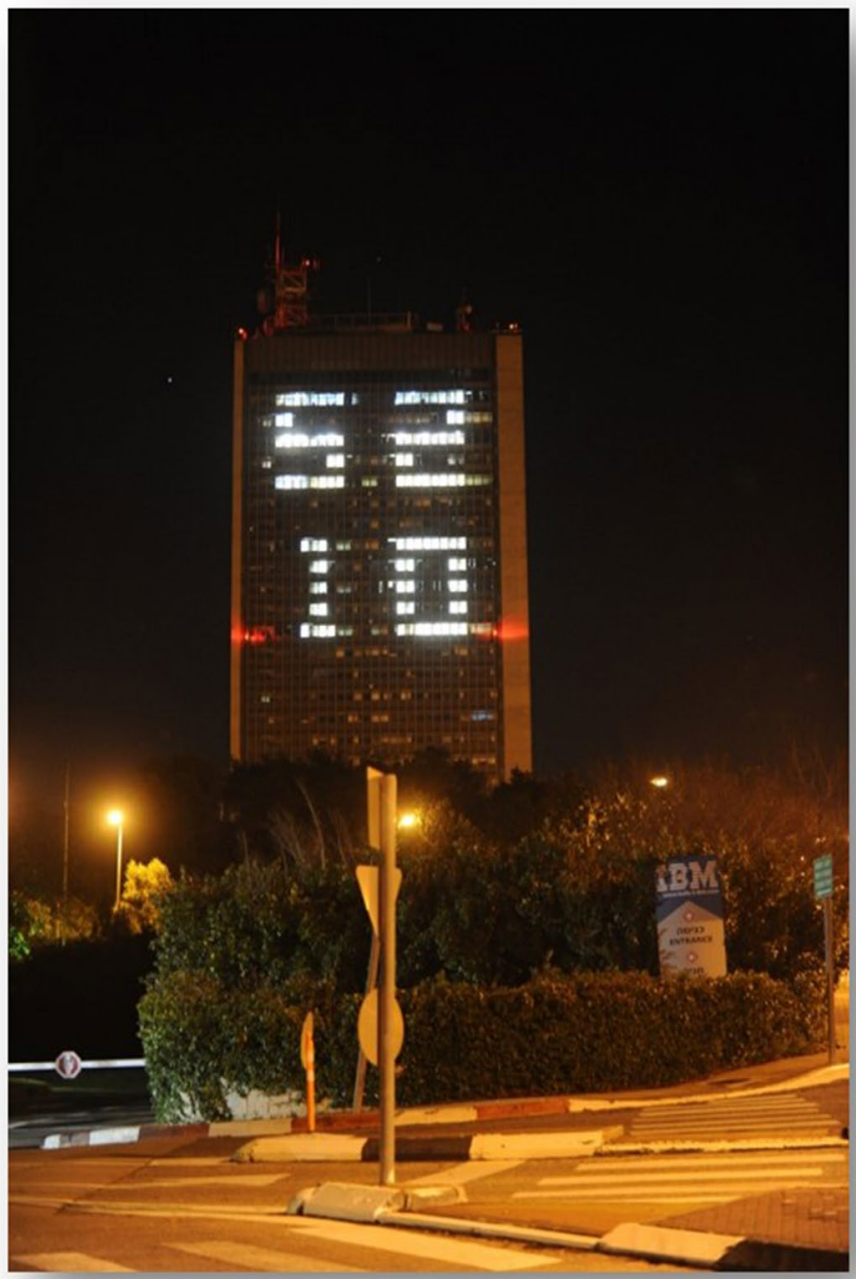

Fig. 3 Project "Fresh Start": University of Haifa's Eshkol Tower

was named (25.10, reading numeral counter-clockwise); some people thought that the 5 and 2 depicted a Menorah because the event took place around the Jewish holiday of Hanukkah; and, my favorite answer "52-10=42", the answer to the Ultimate Question of Life, the Universe, and Everything, according to the Hitchhiker's Guide to the Galaxy, by Douglas Adams.

All these answers are wrong.

The correct answer was that these numbers reference a project by the World Health Organization that attempts to help people obey four basic rules of good 
health conduct: 5 stands for "Eat five or more fruits and vegetables"; 2 is "Use your computer screens and cellphone screens for $2 \mathrm{~h}$ or less every day"; 1 is "Exercise for at least one hour a day"; and 0 is "Do not drink any sugary drinks". The project aimed at bestowing people with the opportunity for a fresh start of these basic healthy habits.

Recently, I have engaged in a new project, with Meira Levy and Israecl Rechevski, the first stage of which includes documenting changes people have decided to make, after getting a chance of pausing the and thinking due to the Coronavirus-fighting restrictions imposed on their daily lives. For instance, some people decided to read a book, others to exercise more, and some even to start new careers. Later, in the next phase of this project, having documented the switches, we intend to provide mechanisms to support these aspired changes for the benefit of people.

Coronavirus provided us with an opportunity to devise ways to keep good changes that are occurring these days while overcoming the pandemic. I call for implementing behavioral economics tools such as to help with paving the path to achieving this goal.

\section{References}

OECD (2020). https://www.oecd.org/about/. Report may be downloaded after subscription

Oxford Economics, (2020). https://www.oxfordeconomics.com/. Report may be downloaded after subscription.

The Guardian, April 11 (2020): https://bit.ly/2LfTgMz.

Publisher's Note Springer Nature remains neutral with regard to jurisdictional claims in published maps and institutional affiliations. 